\title{
Estágio em Psicologia Escolar e Arte: Contribuições para a Formação do Psicólogo
}

Internship In School Psychology And Art: Contributions To
The Professional Formation Of The Psychologist

Pasantía En Psicología Escolar Y Arte: Contribuciones Para La Formación Del Psicólogo

Silvia Maria Cintra da Silva, Luciana Guimarães Pedro, Dami da Silva, Diogo Rezende \& Laís Miranda Barbosa

Universidade Federal de Uberlândia
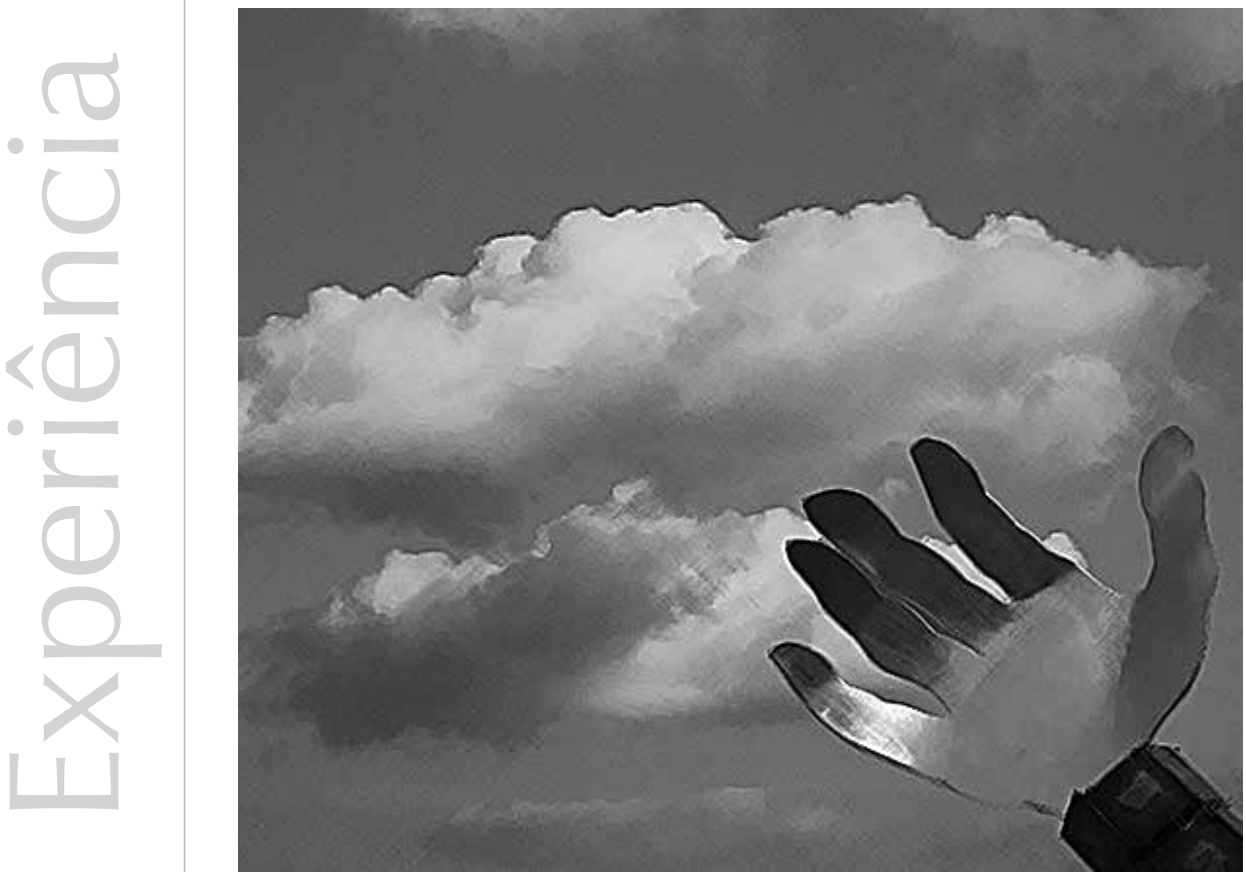
Resumo: O presente trabalho relata as experiências vivenciadas em um estágio de Psicologia escolar realizado no Curso de Psicologia da Universidade Federal de Uberlândia (UFU). O estágio, pautado na Psicologia histórico-cultural, estava vinculado à organização e ao desenvolvimento de uma disciplina intitulada Psicologia: Ciência e Profissão, voltada para os alunos que ingressavam no referido curso. A ementa dessa disciplina vai ao encontro da necessidade de desenvolvimento de uma visão crítica e socialmente comprometida em relação à Psicologia, o que permite a constituição de um espaço de possibilidades de se considerar essa ciência e profissão de um modo mais amplo. As atividades desenvolvidas nos encontros buscavam instigar reflexões acerca da Universidade, da Psicologia como ciência e profissão e da vida acadêmica. Para embasar essas discussões, a Arte (cinema, pintura, teatro, literatura, música) foi utilizada como mote para a apropriação e a construção do próprio conhecimento. Descrevemos aqui a trajetória desse estágio e as suas repercussões na formação pessoal e profissional dos futuros psicólogos, dando destaque para as contribuições desencadeadas a partir do contato com a Arte tanto para os estagiários como para a supervisora.

Palavras-chave: Artes. Formação do psicólogo. Psicologia escolar. Supervisão clínica.

Abstract: This paper describes the experience acquired during a school psychology internship in the psychology course in the Federal University of Uberlândia (UFU). The internship, based on the culturalhistorical psychology, was linked to the organization and development of a course titled Psychology: Science and Profession, which is oriented towards freshmen students. The program of this course meets the need to develop a socially involved and critical vision of psychology, which allows the creation of a space of possibilities to think about this science and profession more broadly. The activities developed in the meetings sought to engage reflections about the University, about psychology as a science and profession and about the academic life. To serve as base for discussion, Art (cinema, painting, theatre, literature, music) was used as a theme for ownership and construction of self knowledge. We describe the results of the internship and its impact on the personal and professional education of future psychologists, highlighting the contributions triggered by the contact with Art.

Keywords: Arts. Professional formation. School psychology. Clinical supervision.

Reseumen: El presente trabajo relata las experiencias vividas en una pasantía de Psicología escolar realizada en el Curso de Psicología de la Universidad Federal de Uberlândia (UFU). La pasantía, pautada en la Psicología histórico-cultural, estaba vinculada a la organización y al desarrollo de una disciplina titulada Psicología: Ciencia y Profesión, volcada a los alumnos que ingresaban en el referido curso. El contenido programático de esa disciplina va al encuentro de la necesidad de desarrollo de una visión crítica y socialmente comprometida con relación a la Psicología, lo que permite la constitución de un espacio de posibilidades de considerarse esa ciencia y profesión de un modo más amplio. Las actividades desarrolladas en los encuentros buscaban incitar reflexiones acerca de la Universidad, de la Psicología como ciencia y profesión y de la vida académica. Para la base esas discusiones, el Arte (cine, pintura, teatro, literatura, música) fue utilizado como recurso para la apropiación y la construcción del propio conocimiento. Describimos aquí la trayectoria de esa pasantía y sus repercusiones en la formación personal y profesional de los futuros psicólogos, dando destaque para las contribuciones desencadenadas desde el contacto con el Arte tanto para los practicantes como para la supervisora.

Palabras-clave: Artes. Formación del psicólogo. Psicología escolar. Supervision clinica.

1 Este nome, pensado no momento em que o projeto pedagógico do curso de Psicologia da UFU estava sendo reformulado a partir das Novas Diretrizes Curriculares (2004), foi tomado de empréstimo à revista Psicologia: Ciência e Profissão, do Conselho Federal de Psicologia, por contemplar de modo dialético os dois principais âmbitos da Psicologia: teoria e prática, pesquisa e atuação profissional.
Este artigo apresenta o relato de uma experiência de estágio supervisionado em Psicologia escolar no ensino superior, vinculado à organização e ao desenvolvimento de uma disciplina intitulada Psicologia: Ciência e Profissão ${ }^{1}$, oferecida aos alunos que ingressavam no curso de Psicologia. Pautada na Psicologia histórico-cultural, essa proposta utilizou a Arte como elemento mediador para a formação pessoal e profissional dos futuros psicólogos, estagiários e calouros. Descrevemos aqui tanto o estágio em si como a trajetória vivenciada pelos estagiários e pela supervisora e a repercussão dessa experiência em suas vidas.

\section{O estágio em Psicologia Escolar e Arte}

A Psicologia foi gestada com base na crença da neutralidade científica, na possibilidade de apreensão da realidade de maneira objetiva e imparcial, assumindo um posicionamento supostamente acrítico que colabora e 
Ainda sob os auspícios dessa lógica, muitas vezes os cursos de Psicologia têm formado profissionais que não conseguem criticar ou refletir sobre a realidade, reproduzindo em sua prática profissional os ideais de alienação, aceitação e conformidade vigentes (Meira, 2003; Souza \& Silva, 2009). obedece à lógica social capitalista, já que seu desenvolvimento reflete interesses históricos, sociais e políticos. Como escreve Patto, no percurso de sua constituição científica, a Psicologia "vem para dizer quem são os normais e os mais aptos e, assim, repor a ilusão de igualdade em sociedades congenitamente desiguais" (2007, p. 4). Ainda sob os auspícios dessa lógica, muitas vezes os cursos de Psicologia têm formado profissionais que não conseguem criticar ou refletir sobre a realidade, reproduzindo em sua prática profissional os ideais de alienação, aceitação e conformidade vigentes (Meira, 2003; Souza \& Silva, 2009). Nessa perspectiva, entendem-se os problemas psicológicos como individuais, com explicações intrapsíquicas e desconsiderando as condições sociohistóricas em que são forjados. Assim, a Psicologia muitas vezes torna-se uma ferramenta de adequação e de ajustamento do indivíduo, não se pautando pela crítica e pela compreensão social.

Considerando as consequências desse posicionamento e a necessidade do desenvolvimento de uma Psicologia crítica, ampliada e norteada pela perspectiva histórico-cultural, em 2004, foi organizado um estágio intitulado Psicologia Escolar e Arte, voltado para a realização de projetos de intervenção na referida área junto aos alunos que ingressavam no Curso de Psicologia da Universidade Federal de Uberlândia (UFU). Além disso, o descontentamento com o curso relatado pelos calouros, aliado à evasão que incidia sobre os primeiros semestres, reiteraram a necessidade de uma ação que focalizasse os estudantes logo no início de sua vida acadêmica.

No princípio, o estágio era uma atividade optativa de caráter informal, caracterizado por encontros realizados semanalmente com os calouros, em horários fora das aulas regulares, e contava com a participação de quatro estagiários veteranos do curso de Psicologia, sob a orientação da professora supervisora. O seu intuito era acolher o calouro do curso em sua entrada na Universidade, buscando integrá-lo ao ambiente universitário, tendo a Arte como intermediária desse contato. A Arte tinha, então, um espaço para ser vivenciada e experimentada dentro do universo acadêmico, e os calouros eram incentivados a refletir de maneira crítica acerca da Universidade e da Psicologia a partir do contato com poemas, músicas e filmes. Esse estágio permaneceu nesse formato durante quatro anos e meio.

Com a implementação do novo Projeto Pedagógico baseado nas Diretrizes Curriculares para os cursos de Psicologia (Brasil, 2004), esse projeto se transformou em uma disciplina obrigatória chamada Psicologia: Ciência e Profissão, oferecida aos estudantes do primeiro período, com foco na Arte, nas questões acadêmicas e na Psicologia. Essa disciplina tem um caráter diferenciado das demais que compõem o Projeto Pedagógico da UFU, pois é conduzida prioritariamente por quatro estagiários, sob orientação da professora responsável; as aulas têm caráter de encontros, já que apresentam uma didática mais criativa, prezando a reflexão e a participação ativa dos alunos, e a própria avaliação é singular, uma vez que é feita a partir da realização de seminários sobre Arte e artigos científicos de Psicologia e da confecção de um portfólio inspirado nesses encontros e naquilo que foi mais significativo entre as vivências dos discentes.

Nessa nova configuração, a disciplina tem, assim como o projeto inicial desenvolvido anos antes, o intuito de proporcionar aos alunos que ingressam no curso reflexões sobre a Universidade e a vida acadêmica, sobre a Psicologia como ciência e profissão e sobre a importância das diversas linguagens artísticas para a formação pessoal e profissional do indivíduo, considerando-se a dicotomia que geralmente acontece entre esses âmbitos no 
...Vigotski "A arte é o social em nós, e, se o seu efeito se processa em um indivíduo isolado, isso não significa,

de maneira nenhuma, que as suas raízes e essência sejam individuais" (1925/1999a, p. 315). contexto educativo, já que os conteúdos acadêmicos são valorizados em detrimento das demais formas de conhecimento. A disciplina tem também como objetivo criar um espaço de trânsito de informações para orientar os alunos do primeiro período, sanar possíveis dúvidas, oferecendo apoio para as atividades acadêmicas, instigar a participação dos calouros nas diversas atividades oferecidas pela Universidade, refletir acerca da Psicologia de maneira mais ampla, além de incentivar o contato com a Arte, considerada fundamental para a formação pessoal e profissional do sujeito, já que é produto da atividade humana e reflexo da dimensão social em nós, como afirma Vigotski "A arte é o social em nós, e, se o seu efeito se processa em um indivíduo isolado, isso não significa, de maneira nenhuma, que as suas raízes e essência sejam individuais" (1925/1999a, p. 315).

A arte ocupa lugar privilegiado no estágio e na disciplina em si, pois o cinema, as artes visuais, a música, a literatura e o teatro são utilizados como mote para a apropriação e a construção do próprio conhecimento pelos estagiários, fomentando o desenvolvimento do pensamento crítico. Seja como pano de fundo para as atividades propostas, seja como protagonista ao instigar reflexões e/ou a própria fruição artística, a Arte é elemento mediador para provocar, junto aos alunos que ingressam, pensamentos sobre si mesmos, sobre o outro, sobre as relações e os contextos em que estão inseridos e sobre os quais atuarão, possibilitando o surgimento de distintos olhares e de subsídios diferenciados para o desenvolvimento de uma prática profissional engajada e socialmente comprometida. Nesse sentido, ao abordar a formação e a atuação do psicólogo, Saraiva escreve sobre a necessidade de

construir espaços onde seja possível e necessário (re)aprendermos a olhar, de que tanto precisamos. (Re)aprendermos a olhar o que o outro sabe, tem e pode, enfim, olhar o que acontece, o que se afirma, de forma a podermos nos adequar a expressões, valores e gostos, ao invés do outro ter de adequar-se àquilo que sabemos perguntar (2007, p. 75)

A Psicologia histórico-cultural é utilizada como aporte teórico na escolha dos textos, nas discussões e em todas as atividades desenvolvidas ao longo da disciplina. Assim, parte-se do princípio de que o desenvolvimento do psiquismo é sociohistórico, pois estrutura-se na atividade social dos indivíduos e se dá pelos processos de objetivação e de apropriação da cultura humana, ou seja, o desenvolvimento humano é determinado pelo contexto histórico e social em que se está inserido. Assim, o homem deve ser compreendido partindo-se das relações que produz (e onde também se constitui), das relações sociais objetivas, considerando-se o caráter concreto da sua vida social e individual (Meira \& Facci, 2007).

Nessa perspectiva, a proposta da disciplina de propiciar a formação crítica dos alunos de Psicologia por meio do contato com a Arte, um dos aspectos da cultura humana, vai ao encontro dos preceitos da teoria históricocultural e da necessidade de contribuir para que a Universidade cumpra seu papel de socialização do saber e de formação crítica dos alunos, favorecendo o seu processo de humanização e o desenvolvimento do seu pensamento crítico.

Em relação à Arte, sabemos que existem diversas definições. Coli, por exemplo, afirma que:

A arte tem em si uma função que poderíamos chamar de conhecimento, de 'aprendizagem'. Seu domínio é o do nãoracional, do indizível, da sensibilidade: domínio sem fronteiras nítidas, muito diferente do mundo da ciência, da lógica, da teoria. Domínio fecundo, pois nosso contato com a arte nos transforma, porque o objeto artístico traz em si, habilmente organizados, os meios de despertar em 
nós, em nossas emoções e razão, reações culturalmente ricas, que aguçam os instrumentos dos quais nos servimos para apreender o mundo que nos rodeia. (1995, p. 109)

A Arte é um veículo de sensibilização do homem, e, por conseguinte, pode potencializar a compreensão do psicólogo acerca do mundo e das emoções humanas, que estão no foco do seu trabalho. Ao possibilitar o contato com o novo, com o diferente e com o imprevisível, traz elementos preciosos para a seara da Psicologia, o que é fundamental para o trabalho do psicólogo, já que este lida com miríades constitutivas do sujeito. Para Silva (2005), a Arte amplia nosso universo de referências, gera estranhamentos com os quais aprendemos e somos conduzidos a um mundo até então desconhecido.

Vázquez, por sua vez, considera a Arte produção humana, fruto do trabalho e resultado de toda a história da humanidade. Para esse autor, o objeto estético possibilita a afirmação das potencialidades humanas no mundo objetivo, já que "o produto artístico é uma totalidade única e irrepetível" (2010, p. 101). E o autor completa dizendo que a Arte é o reduto inexpugnável da capacidade criadora do homem, é o espaço em que sua condição humana se afirma e se revela da maneira mais plena e livre.

Toda obra de Arte, segundo Vigotski (1987), é sempre produto de sua época e do seu contexto; assim, para o psicólogo, o contato com a Arte pode permitir maior entendimento sobre sua realidade concreta, realidade essa que o constitui e que, em consequência, por ele é constituída, possibilitando-lhe aprofundar o entendimento sobre o ser humano, que é seu objeto de estudo.

Podemos considerar, como Pino, que uma das grandes contribuições - e inovações - que Vigotski traz à Psicologia é fazer da cultura "a categoria central de uma nova concepção do desenvolvimento psicológico do homem" (2005, p. 35). Essa categoria rompe uma visão naturalizante a respeito do homem e gera uma importante mudança qualitativa no debate da Psicologia acerca do desenvolvimento humano.

Vigotski (2003) assinala o caráter social, cultural e histórico dos processos mentais superiores, constituídos na dinâmica da interação do sujeito com seu mundo cultural. A apropriação da cultura acontece de maneira transformadora: o homem altera as atividades externas ao seu organismo e as interações com o outro em atividades internas e intrapsicológicas.

De acordo com Zanella et al.,

Contextos de ensinar e aprender são, portanto, contextos de produção de significações em que os sujeitos em relação ativamente produzem aos outros como a si mesmos. Isso porque aprender, de acordo com a Psicologia histórico-cultural, consiste na apropriação ativa (e não adaptação, introjeção literal do percebido) das significações das produções humanas que caracterizam a realidade como universo semiótico: é um meio para a humanização, posto que possibilita a constituição de modos mais complexos e elaborados de regulação pelo próprio sujeito de sua conduta e vontade. (2004, p. 96)

Considerando-se a importância dos processos educacionais na apropriação dos elementos Culturais, cabem, então, algumas ponderações sobre a formação profissional, a arte e a Universidade. Ao tratar da função da Universidade pública, Chauí define formação da seguinte maneira:

O que significa exatamente formação? Antes de mais nada, como a própria palavra indica, uma relação com o tempo: é introduzir alguém ao passado de sua cultura (no sentido antropológico do termo, isto é, como ordem simbólica ou de relação com o ausente), é despertar alguém para as questões que esse passado engendra para o presente, e é estimular a passagem do instituído ao instituinte. (2003, p. 8) 
Nas reflexões trazidas pela autora, a obra de arte também comparece como elemento fundamental, pois, ao estabelecer o novo sobre o que estava assentado firmemente na cultura, ela "reabre o tempo e forma o futuro" (2003, p. 8). Assim, só há formação quando há obra de pensamento, e esta só pode existir quando há um trabalho de questionamento, de problematização e de crítica, com a possibilidade de conceitualização daquilo que antes foi problematizado.

Ribeiro também traz ponderações importantes acerca do papel da Universidade para a formação ampliada do estudante, no sentido de propiciar-lhe o que denomina "poliglotismo cultural" (2001, p. 32): a capacidade de estabelecimento de uma interlocução profunda e vigorosa com os diferentes campos do saber.

Assim, o estágio propicia ao futuro psicólogo a importante experiência de entrar em contato com a realidade profissional, sendo um momento decisivo na formação por abarcar também, nesse contato com efetivas possibilidades de prática, a materialização de competências e de habilidades necessárias ao exercício efetivo da profissão. Nesse sentido, o espaço criado pelos supervisores de estágio (considerando-se as interações propiciadas na e pela supervisão) apresenta-se como terreno fecundo para a composição de trajetos e de estratégias que permitam ao estagiário construir possibilidades de atuação em seu processo de constituição profissional. O estágio precisa ter como um de seus principais objetivos a criação de condições para que o aprendiz se desenvolva em circunstâncias de fato representativas da atividade profissional, experienciando o papel de psicólogo e, desse modo, colocando em prática o conhecimento adquirido no curso até esse momento. Consideramos que o estágio seja o momento do curso em que o aluno tem a possibilidade de aliar as competências básicas até então desenvolvidas (os aspectos metodológicos, teóricos, instrumentais e éticos da formação) à teoria, para então realizar seu trabalho e refletir criticamente sobre a realidade em que se insere e em que desempenha tal atividade.

Assim, como observa Matos,

Desejamos um psicólogo que seja mais que um mero técnico ou 'aplicador' de conhecimentos, e que esteja preparado para um uso criativo do conhecimento psicológico. Isso supõe uma articulação entre teoria e prática, entre as práticas psicológicas e suas dimensões e incidências sociais. (2000, p. 14)

Na relação de aprendizado profissional, de acordo com Pires, "a troca de experiência é fundamental; constitui o próprio objeto de tal relação, porque possibilita ao aluno orientado pelo professor e seus pares se apropriar de modos de elaboração e atuação profissional" (2011, p. 107).

Partindo da discussão até aqui apresentada, a seguir trazemos contribuições de um estágio que trouxe a Arte como elemento para falar da Psicologia como ciência e profissão, uma Psicologia crítica, reflexiva e que considera as condições socio-históricas no seu modo de compreensão do homem. Descrevemos aqui as riquezas de um estágio que utilizou a Arte para fecundar a ciência (Ribeiro, 2001).

\section{As supervisões de estágio}

As supervisões do estágio eram realizadas semanalmente com a duração média de três horas, com a participação dos quatro estagiários e da professora supervisora. $\mathrm{O}$ objetivo era, além de organizar a programação dos encontros com os alunos, fazer com que os estagiários se apropriassem das diversas linguagens artísticas, refletissem de maneira crítica sobre o papel da Psicologia e a sua implicação na dimensão social e ensaiassem um novo olhar sobre o outro, para poderem, 
então, conduzir encontros diferenciados com os calouros, possibilitando a estes o contato com essa ciência de maneira mais ativa, implicada e crítica. Para isso, expúnhamos reflexões e críticas sobre os temas principais do estágio, compartilhávamos impressões, emoções e sentimentos a respeito dos encontros com os alunos e experimentávamos a Arte de modo mais intenso por meio da leitura e da apreciação de contos, poemas, músicas, filmes e reproduções de obras de arte.

Alguns dos vários textos discutidos para o embasamento teórico e preparação das atividades do estágio foram: A Psicologia em Questão, de Maria Helena Souza Patto (2007), Olhares em Foco: Tensionando Silenciamentos, de Luiz Fernando de Oliveira Saraiva (2007), dentre outros, além da leitura de alguns livros, como, por exemplo, O que é Arte, de Jorge Coli (1995), Cartas a um Jovem Terapeuta, de Contardo Calligaris (2008), e Cinema \& Educação, de Rosália Duarte (2002), e também de contos como Felicidade Clandestina, de Clarice Lispector (2000), Um General na Biblioteca, de Italo Calvino (1993), e Manuscrito Achado num Bolso, de Júlio Cortázar (2000).

Desse modo, como a Arte ocupou lugar central no estágio, durante as supervisões, houve momentos para frú́-la, como dito acima, e para dialogar abertamente sobre essas obras e suas repercussões nos estagiários e na supervisora e na formação profissional dos alunos. Também foram partilhadas reflexões, dificuldades e descobertas possibilitadas pelo contato com o material teórico e artístico do estágio, das supervisões e dos encontros com os calouros. Dentre a produção artística apreciada ao longo do ano, além da literatura, citamos, por exemplo, os filmes Palavra (En)cantada, Camelos também Choram, Arca Russa, músicas de compositores e intérpretes como Chicas, Comadre Fulôzinha, Jane Duboc, Grupo
Anima, etc. Além disso, realizamos visitas ao Museu Universitário de Arte (MUnA) da Universidade Federal de Uberlândia, para ver exposições de arte contemporânea.

A seleção de filmes, poemas, músicas, etc., tanto para as supervisões quanto para os encontros com os calouros, era feita pela supervisora e pelos estagiários, sendo que o critério para a escolha de todas as obras utilizadas foi o não pertencimento à grande mídia, ao circuito comercial, o fato de não compartilhar a lógica hollywoodiana de mercado, de estar ausente do circuito comercial, a fim de possibilitar o contato com outras produções, como o cinema iraniano, a poesia marginal e a vanguarda musical paulistana. Acredita-se que apresentar aos calouros obras de arte que não são de fácil circulação possa auxiliá-los no desenvolvimento de novas organizações do pensamento, uma vez que seria desafiador conseguir refletir sobre uma linguagem artística oferecida de modo diferente do convencional. Além disso, cabe acrescentar que os alunos que ingressam no curso não participaram diretamente dessa seleção, o que é um ponto a ser repensado para a organização da disciplina, considerando-se que a proposta em questão visa a valorizar a participação e a construção coletiva do conhecimento.

Tais experiências foram extremamente valiosas para a formação dos estagiários e da supervisora, já que contribuíram para a ampliação do olhar sobre a Psicologia, a Arte e a condição humana. Bronowski destaca a singularidade dos sujeitos, que se constituem a partir de “(...) uma ordenação particular de tudo aquilo que compartilhamos como seres humanos. O que faz a obra de arte é encontrar uma abertura, uma faceta do caleidoscópio que sirva de porta para esse reconhecimento" (1983, p. 116). A fruição de cada um dos itens acima mencionados permitiu-nos olhar de outros modos para 
nós mesmos, para o outro e para a Psicologia como profissão e ciência.

\section{Os encontros com os calouros}

Os encontros ${ }^{2}$ da disciplina Psicologia: Ciência

e Profissão foram realizados semanalmente com os calouros, e tiveram a duração de uma hora e quarenta minutos. Algumas atividades ocorriam com toda a turma, composta por quarenta alunos; em outras, a turma era divida em dois grupos, de modo que cada dupla de estagiários se responsabilizava pela condução de um deles. Entendemos essa configuração como mais propícia para as discussões que provocávamos, especialmente nos casos de estudantes que encontravam mais dificuldade para se expressar no grupo maior.

Sendo coerente com seu caráter particular, a disciplina iniciou-se com atividades diferenciadas já na semana de recepção aos calouros. Começamos com uma apresentação dos alunos, dos estagiários e da professora, em que foi solicitado que, além da apresentação pessoal, cada um citasse um filme, um livro ou música de que gostasse muito e que o caracterizasse. Também fizemos uma reunião com os pais dos calouros com o intuito de acolhê-los no momento de entrada dos filhos na Universidade e de apresentar-lhes o universo acadêmico do qual eles também se tornariam parte; além disso, ainda exibimos um filme não comercial, buscando, logo no início do curso, instigar o olhar dos que ingressavam para outras formas de narrativa cinematográfica.

No início da disciplina, foi feito um contrato em que os alunos, os estagiários e a professora supervisora discutiram e combinaram aspectos relativos à dinâmica de funcionamento e à organização dos encontros para que estes fossem mais bem aproveitados. Para isso, os alunos deveriam dividir-se em grupos de quatro pessoas e fazer um levantamento das sugestões. Após a leitura e discussão destas, foram esclarecidas as dúvidas e listados os pontos que iriam compor o contrato e nortear as atividades realizadas durante todo o semestre.

Como preparação para os encontros, era sugerido que os alunos lessem tanto textos acadêmicos quanto contos e poemas, que subsidiariam as discussões sobre os diferentes assuntos, ligados à Psicologia e também sobre a Arte e os debates sobre os filmes. De modo geral, foram desenvolvidas atividades diversas, como: apresentação e debate sobre o Guia Acadêmico oferecido pela Universidade, palestra sobre a loucura com uma profissional que atuava na área, visitas ao Setor de Psiquiatria do Hospital de Clínicas de Uberlândia, à biblioteca da Universidade e ao Museu Universitário de Arte, debate sobre o movimento estudantil e o trote universitário (banido da UFU), apresentação e discussão sobre o Sistema Conselhos de Psicologia, questões éticas ligadas à prática profissional, palestras com estagiários de diferentes campos de trabalho e perspectivas teóricas que visavam a apresentar as possíveis áreas de atuação do psicólogo.

Além das atividades supracitadas, também conversamos a respeito de cinema, apresentamos filmes e mediamos reflexões acerca dos textos, poemas e contos sugeridos ao longo do semestre. Ainda nesse sentido, criamos a overdose de arte, um encontro em que os participantes pudessem apreciar e experimentar de forma intensa a Arte em suas diversas manifestações. Para essa atividade, a sala de aula foi esvaziada das carteiras e organizada como uma grande instalação, composta por cantos temáticos - música, varal de literatura, cinema, pintura - que podiam ser percorridos pelos participantes de maneira livre e espontânea, permitindo que interagissem com as diversas obras e também que se expressassem por meio da escrita e do desenho, registrando de modo pessoal as impressões dessa vivência. 
Nos encontros, era instigada a fruição das obras, tanto no sentido da apreciação da Arte em si, considerando elementos da própria linguagem, como no sentido de que determinadas obras mediavam a discussão a respeito de temas específicos da Psicologia. A leitura do conto Um General na Biblioteca, de Italo Calvino (1993), por exemplo, logo nos primeiros encontros com os calouros, provocou uma conversa interessante sobre o modo como o conhecimento é disponibilizado intencionalmente, no sentido da alienação dos sujeitos. Outro momento que exemplifica discussões suscitadas a partir do contato com as obras de arte foi o debate sobre o filme Persépolis (Satrapi \& Paronnaud, 2008), que desencadeou temas acerca da condição da mulher no Ocidente e no Oriente, feminismo, críticas sobre a metodologia de ensino na Universidade e a participação discente no movimento estudantil.

Não havia um estudo técnico específico sobre as linguagens artísticas, mas, como recomenda Ostrower, para que não se caia em um reducionismo quando se busca compreender/ler uma obra de arte, é importante considerar que "as significações que a obra tem, que ela a um tempo funde e comunica, só podem ser compreendidas respeitando-se os termos de linguagem usados (...)" (2001, p. 48) pelo artista que a elaborou. Assim, quando utilizávamos um filme, por exemplo, buscávamos explorar também elementos da própria linguagem cinematográfica nas discussões, como fotografia, roteiro e inserção do filme na história do cinema.

Durante os encontros, as atividades eram conduzidas sempre em círculo, de modo que todos os participantes tivessem a possibilidade de expressar-se segundo a sua vontade; debatíamos focando os pontos que mais os afetassem, e alguns temas e experiências em especial provocaram intensa discussão e envolvimento dos calouros, como a visita à psiquiatria, a conversa sobre as questões éticas da atuação do psicólogo e a overdose de arte.

Notamos que mesmo a configuração circular no ensino superior sendo bastante prosaica, para os estudantes que estão chegando do ensino médio, ela ainda causa certa estranheza, por virem de um desenho de sala de aula que ainda os agrupa de forma tradicional, em fileiras. A formação em círculo ajuda a desfazer a impressão de que quem está à frente é o mestre, pois nessa configuração, há uma continuidade no alinhamento, sem privilegiar-se um determinado lugar para o discurso.

\section{Algumas reflexões sobre a proposta}

Embora a proposta da disciplina não seja convencional, foi necessário, entretanto, elaborar um modo de avaliação que tanto contemplasse as exigências curriculares quanto respeitasse o seu caráter inovador. Assim, propusemos a realização de dois seminários em grupo: o primeiro abordando artigos científicos de Psicologia ${ }^{3}$ e outro seminário sobre Arte, com ênfase em alguma linguagem ou movimento artístico, como, por exemplo, música, cinema ou teatro. Nosso intuito foi despertar o interesse dos calouros pela produção científica nacional e instigar a busca e a apreciação de conteúdos artísticos.

Outra modalidade avaliativa foi a confecção e a apresentação de um portfólio final contendo as reflexões e os comentários dos alunos sobre todos os encontros e as atividades desenvolvidas na disciplina (Villas Boas, 2004). A escolha pelo portfólio ocorreu devido ao seu caráter contínuo e processual, e possibilitou grande autonomia na escolha e na apresentação dos tópicos que o estudante considerava mais importantes bem como o exercício da criatividade na sua elaboração. 
É importante ressaltar nossa surpresa, ao final dos semestres, com a criativa e cuidadosa elaboração dos portfólios apresentados e com o relato dos participantes sobre a disciplina. Os portfólios foram preparados em formatos diversos, como: cadernos com poemas de autoria dos próprios estudantes e reflexões sobre os encontros, travesseiro de papel celofane recheado com pequenos pedaços de papel que continham ideias noturnas sobre os temas discutidos ao longo do semestre, varal com vários símbolos da Psicologia (a letra grega psi) feitos em papel cartão com depoimentos sobre os encontros no verso, um laudo criminal feito em pasta preta, revelando a intimidade e as reverberações da disciplina, uma bonecabebê de plástico, repleta de rolinhos de papel afixados pelo corpo contendo novas ideias que a constituíam e a transformavam, um cérebro esculpido em resina contendo milhares de ideias em seu interior escritas em pedaços de papel, um disco de vinil acomodado em um encarte personalizado, repleto de músicas e de ideias sobre as experiências vivenciadas na disciplina, um pé de romã carregado de frutos de papel, com depoimentos escritos na parte interna, uma caixinha decorada com fichas repletas de reflexões, jogos de tabuleiro com instruções e orientações completas que compunham um jogo sobre grande parte das discussões feitas em sala, um jogo de amarelinha feito de papel com depoimentos e perguntas em cada um dos quadrados que a compunham, um pote com gel, à guisa de água, onde estavam mergulhadas diversas reflexões em papel plastificado, etc.

Constatamos, assim, que o portfólio pode ser um método avaliativo prazeroso e desafiador, que proporciona a apropriação do conhecimento e a autonomia dos alunos de maneira criativa dentro do contexto universitário. Para a supervisora e os estagiários, o desafio foi encontrar formas para avaliar uma produção tão pouco usual; consideramos como critérios a criatividade na apresentação e conteúdo que apresentasse, minimamente, o percurso do calouro ao longo do semestre na disciplina Psicologia: Ciência e Profissão e no curso de forma geral.

$\mathrm{Na}$ avaliação da disciplina, os comentários dos ingressantes abordaram o tom inovador, a possibilidade da escrita autoral, o contato com uma produção cultural até então desconhecida para muitos, o estranhamento em relação a muitas obras. Em seus relatos ao final de cada semestre, focalizaram enfaticamente sentimentos e reflexões desencadeadas pela Arte, propiciadas pelas oportunidades muito diversas das experienciadas até então, seja na escola, seja na família. Também destacaram o cuidadoso acolhimento pelos estagiários no momento tão especial que é a entrada na Universidade.

Os estagiários, por sua vez, ao conhecerem a organização e a dedicação necessárias para o desenvolvimento de uma disciplina na graduação, encantaram-se com o próprio aprendizado e o dos novos colegas de curso, puderam apreciar mais de perto o universo dos calouros e conseguiram constatar a síntese das vivências desencadeadas pela disciplina por meio do portfólio. Ao ocuparem os papéis de alunos veteranos/estagiários e até mesmo de docentes, sentindo-se muito desafiados nessas funções, puderam viver e refletir sobre experiências fundamentais para sua formação pessoal e profissional.

\section{Considerações finais}

De acordo com a teoria histórico-cultural, as interações sociais são essenciais para o desenvolvimento do psiquismo humano, desenvolvimento esse fundamentado pela apropriação de formas mais elaboradas de atividades, e, como afirma Silva (2005), no contato com as obras de arte, as funções psicológicas superiores encontram terreno fecundo para seu desenvolvimento. Assim, 


\section{Conforme Araújo}

(2001) bem

questiona,

se a escola

não se incumbir

da missão de

desvelar o mundo

mágico da arte,

continuaremos

a ver formaremse médicos, engenheiros, advogados, economistas

(...) que nunca vibraram com

a leitura de um

romance, nunca

umedeceram os

olhos com um

soneto, nem se

enlevaram ao

ouvir uma sinfonia.

Mas que ser

humano é esse?

Que educação é essa? (2001, p. 26) a proposta de estágio aqui apresentada possibilitou, para os estagiários, um contato profundo com a Arte, que interveio tanto como veículo para a discussão de elementos da disciplina Psicologia: Ciência e Profissão quanto para conhecimento e fruição de algumas de suas linguagens, como cinema, música, literatura e artes visuais.

Quando colocamos em pauta os movimentos estudantis, as políticas da Universidade, a Psicologia, a teoria histórico-cultural, a formação humana, quando abrimos espaços para as dúvidas e para as discussões sem reservas ou pré-requisitos, estimulando os debates, apostamos que nesses processos os discentes elaborem seus posicionamentos em relação à Psicologia, à formação e à própria vida, tendo como ponto de partida a relação com o outro, seja como cidadão, seja como psicólogo.

Como relatamos acima, ao longo da referida disciplina, procuramos levar o aluno ingressante a considerar, desde o momento de entrada na Universidade, a dimensão subjetiva como dialética e constitutivamente relacionada ao contexto social, sempre visto a partir de um processo histórico e que, para ser entendido, precisa ser olhada por esse contexto (Kahhale \& Rosa, 2009). Além disso, o próprio olhar do futuro profissional necessita ser instigado a desenvolver-se de forma a não se correr o risco de gerar silenciamentos, paralisias, preconceitos, determinações e submissões (Saraiva, 2007).

Vale ressaltar que foram muito importantes as supervisões, as preparações para os encontros e o estar nos próprios encontros com os alunos. As supervisões delinearamse como espaço profícuo para a troca de ideias, partilha da Arte, de conhecimentos e discussões de textos importantes que se tornaram referências profissionais para o trabalho. As preparações dos encontros provocaram inúmeras ideias que circulavam entre estagiários e supervisora e que se articulavam em um processo de construção coletiva do estágio, com a participação de cada um dos envolvidos. A partir da reverberação dos encontros com os calouros, foi consolidando-se a proposta de formação pessoal e profissional em uma perspectiva crítica, ética e socialmente comprometida.

Outra questão importante que merece ser destacada é que, a partir desse estágio, pudemos observar o papel da Universidade como um espaço privilegiado para o contato com a Arte e a ampliação do universo de referência dos graduandos. Nesse sentido, Silva, Machado e Goya (2007) lembram que o acesso ao conhecimento passa necessariamente pela instituição, e, por isso, ela tem uma grande responsabilidade para com os indivíduos, já que possibilita a socialização dos bens culturais e interfere no desenvolvimento psíquico das pessoas.

Conforme Araújo (2001) bem questiona,

se a escola não se incumbir da missão de desvelar o mundo mágico da arte, continuaremos a ver formarem-se médicos, engenheiros, advogados, economistas (...) que nunca vibraram com a leitura de um romance, nunca umedeceram os olhos com um soneto, nem se enlevaram ao ouvir uma sinfonia. Mas que ser humano é esse? Que educação é essa? (2001, p. 26)

Podemos estender tal questionamento para a Universidade, que também é uma escola e que, por isso mesmo, tem o papel de propiciar o contato com a Arte a todos os seus discentes, considerando-se a histórica posição de vanguarda que lhe compete no que se refere à produção, ao ensino e à divulgação do conhecimento.

Partindo do pressuposto que a vivência estética marca de modo permanente o sujeito, as experiências vividas nesse estágio colaboraram para a constituição de todos os envolvidos e, no que se refere aos estagiários, 
auxiliou-os a lidar com a diversidade e a complexidade humanas.

Considerando a Arte elemento especial no estágio aqui apresentado, realçamos o convite que a obra e o autor nos fazem, seja nas notas de uma música, em um jogo de cores, texturas e formas, seja na combinação de palavras que compõem uma narrativa, para dialogarmos, desenvolvendo nossa sensibilidade ao aceitarmos tal convite. Ao tratar da dimensão humana do sujeito, a Arte nos possibilita reflexões acerca de nós mesmos, da vida de modo geral e da sociedade, além de permitir a interlocução com outras obras de Arte e conhecimentos científicos, ampliando nosso conhecimento sobre o homem, a cultura e a sociedade.

Com o relato dessa experiência, queremos reafirmar a importância da Arte como um instrumento diferenciado e privilegiado para a formação crítica do psicólogo, desde sua entrada na Universidade. No diálogo com a Psicologia e disciplinas afins, as diferentes linguagens artísticas podem colaborar para uma formação que considere a importância da dimensão humana em consonância dialética com a dimensão técnica. Assim, as competências e as habilidades apregoadas nas Novas Diretrizes podem respaldar-se também no sustento propiciado pela Arte.

Finalizando, além do incentivo à Arte durante a formação inicial, propomos também uma formação continuada nessa seara para o psicólogo, o que implica tanto a iniciativa pessoal de continuar frequentando a Arte (principalmente se isso já foi constituído socialmente como uma necessidade pessoal) como iniciativas advindas do poder público, de instituições privadas e até mesmo do Sistema Conselhos de Psicologia, algo que já tem sido realizado com a exibição de filmes, por exemplo. Afinal, como escreve Bachelard, "existe um sentido, acreditamos, em falar de análise poética do homem. Os psicólogos não sabem tudo. Os poetas trazem outras luzes a respeito do homem" (1988, p. 120). 


\section{Silvia Maria Cintra da Silva}

Doutora em Educação e docente do Instituto de Psicologia da Universidade Federal de Uberlândia, Uberlândia - MG - Brasil.

E-mail: silvia_ufu@hotmail.com

\section{Luciana Guimarães Pedro}

Mestre pelo Programa de Pós-graduação em Psicologia da Universidade Federal de Uberlândia e docente do Centro Universitário do Cerrado Patrocínio (UNICERP), Patrocínio - MG - Brasil.

E-mail: luciana_udi@hotmail.com

\section{Dami da Silva}

Mestre pelo Programa de Pós-graduação em Psicologia da Universidade Federal de Uberlândia, Uberlândia MG - Brasil.

E-mail: dami_silva@hotmail.com

\section{Diogo Rezende}

Mestrando do Programa de Pós-graduação em Psicologia da Universidade Federal Fluminense, Rio de Janeiro RJ - Brasil.

E-mail: diogoreze@gmail.com

\section{Laís Miranda Barbosa}

Mestranda do Programa de Pós-graduação em Psicologia da Universidade Federal Fluminense, Rio de Janeiro RJ - Brasil.

E-mail: lamiranda.b@gmail.com

Endereço para envio de correspondência:

Avenida Pará, 1720, Bloco 2C, Campus Umuarama. CEP: 38400-902. Uberlândia, MG.

Recebido 15/09/2012, 1a Reformulação 01/07/2013, Aprovado 29/08/2013. 


\section{Referências}

Araújo, A. (2001) Quando a educação descobrir a cultura... In L. A. Aguiar, \& Sobral, M. (Orgs.), Para entender o Brasil. São Paulo: Alegro.

Bachelard, G. (1988). A poética do devaneio (A. de P. Danesi, trad.). São Paulo: Martins Fontes.

Brasil. Ministério da Educação, Conselho Nacional de Educação/ Câmara de Educação Superior. (2004). Parecer no 0062/2004, aprovado em 19/02/2004, fixa as Diretrizes Curriculares Nacionais para os cursos de graduação em Psicologia. Brasília, DF.

Bronowski, J. (1983). Arte e conhecimento - Ver, imaginar, criar (Cardoso, A. L. trad.). São Paulo: Martins Fontes.

Calligaris, C. (2008). Cartas a um jovem terapeuta (2a. ed.). Rio de Janeiro: Elsevier.

Calvino, I. (1993). Um general na biblioteca. In A memória do mundo. Lisboa, Portugal: Teorema.

Chaui, M. (2003). A universidade pública sob nova perspectiva. Conferência na sessão de abertura da $26^{a}$ Reunião Anual da ANPEd, realizada em Poços de Caldas, MG, em 5 outubro, 2003. Recuperado em 30 de maio de 2012 de de http://www. anped.org.br/reunioes/26/inicio.htm

Coli, J. (1995). O que é arte (15a ed.). São Paulo: Editora Brasiliense.

Cortázar, J. (2000). Manuscrito achado num bolso. In Octaedro (4a. ed.). Rio de Janeiro: Civilização Brasileira.

Davaa, B., \& Falorni, L. (Diretores). (2003). Camelos também choram. Mongólia/Alemanha: Europa Filmes.

Duarte, R. (2002). Cinema \& educação. Belo Horizonte: Autêntica.

Kahhale, E. M. S. P., \& Rosa, E. Z. (2009). A construção de um saber crítico em psicologia. In A. M. B. Bock \& M. G. M. Gonçalves (Orgs.), A dimensão subjetiva da realidade: uma leitura sócio-histórica. São Paulo: Cortez.

Lispector, C. (2000). Felicidade clandestina. In I. Moriconi. Os cem melhores contos brasileiros do século. Rio de Janeiro: Objetiva.

Matos, M. A. (2000, jan./dez.). A definição de diretrizes em uma estruturação curricular em psicologia e o estágio de formação profissional. Psicólogo inFormação, 4(4), 11-24. Recuperado em 13 julho, 2011, de http://editora.metodista.br/psicologo1/ psi01.pdf.

Meira, M. E. M. (2003). Construindo uma concepção crítica de psicologia escolar: contribuições da pedagogia históricocrítica e da psicologia socio-histórica. In M. E. M. Meira \& M. A. Antunes. Psicologia escolar: teorias críticas. São Paulo: Casa do Psicólogo.

Meira, M. E. M., \& Facci, M. G. D. (Orgs.). (2007). Psicologia histórico-cultural: contribuições para o encontro entre a subjetividade e a educação. São Paulo: Casa do Psicólogo.

Ostrower, F. (2001). Criatividade e processos de criação (15a ed.). Petrópolis, RJ: Vozes.

Patto, M. H. S. (2007). A psicologia em questão. In M. H. S. Patto
\& J. Frayze-Pereira (Orgs.), Pensamento cruel - humanidades e ciências humanas: há lugar para a psicologia? São Paulo: Casa do Psicólogo.

Pino, A. (2005). As marcas do humano: as origens da constituição cultural da criança na perspectiva de Lev S. Vigotski. São Paulo: Cortez.

Pires, V. S. (2011). O processo de subjetivação profissional durante os estágios supervisionados em Psicologia. (Dissertação de Mestrado). Universidade Federal de Uberlândia, Uberlândia, MG.

Ribeiro, R. J. (2001). (Org.), Humanidades: um novo curso na USP. São Paulo: Editora da Universidade de São Paulo.

Saraiva, L. F. O. (2007). Olhares em foco: tensionando silenciamentos. In B. P. Souza (Org.), Orientação à queixa escolar. São Paulo: Casa do Psicólogo.

Satrapi, M., \& Paronnaud, V. (Diretores). (2008). Persépolis [DVD]. França: Europa Filmes.

Silva, S. M. C. (2005). Psicologia escolar e arte: uma proposta para a formação e atuação profissional. Campinas, SP: Editora Alínea/EDUFU.

Silva, S. M. C., Machado, P. E. R., \& Goya, A. C. A. (2007, jun.), Reflexões sobre o (não) lugar da arte na universidade. In Anais do Il Colóquio de Psicologia da Arte. São Paulo.

Solberg, H. (Diretor). (2008). Palavra (em)cantada (DVD). São Paulo: Radiante Filmes.

Sokurov, A. (Diretor). (2002). Arca Russa (DVD). Rússia: Versátil Filmes.

Souza, M. P. R., \& Silva, S. M. C. (2009). A atuação do psicólogo na rede pública de educação frente à demanda escolar: concepções, práticas e inovações. In C. M. Marinho-Araujo (Org.), Psicologia escolar: novos cenários e contextos de pesquisa, formação e prática (pp.75-105) Campinas, SP: Alínea.

Vázquez, A. S. (2011). As ideias estéticas de Marx (C. N. Coutinho, trad.). São Paulo: Expressão Popular.

Villas Boas, B. M. F. (2004). Portfólio, avaliação e trabalho pedagógico. Campinas, SP: Papirus.

Vygotsky, L. S. (1987). Imaginación y el arte en la infancia. México: Hispânicas, S. A.

Vigotski, L. S. (1999a). A tragédia de Hamlet, príncipe da Dinamarca. São Paulo: Martins Fontes.

Vigotski, L. S. (1999b). Psicologia da arte (P. Bezerra, trad.). São Paulo: Martins Fontes. (Trabalho origina publicado em 1925).

Vigotski, L. S. (2003). Psicologia pedagógica. (Ed. Comentada). Porto Alegre: Artmed.

Zanella, A. V., Da Ros, S. Z., Reis, A. C. dos, \& França, K. B. (2004). Doce, pirâmide ou flor?: o processo de produção de sentidos em um contexto de ensinar e aprender. Interações, 9(17), 91108. Recuperado em 25 maio, 2012 de http://pepsic.bvsalud. org/scielo.php?pid=S1413-29072004000100006\&script=sci arttext 